\title{
PARA EL ESTUDIO DE LOS MUNICIPIOS Y LA POLÍTICA REGIONAL EN MEXICO *
}

\author{
PEDRO PIREZ \\ El Colegio de México
}

\section{INTRODUCCIÓN}

ESTE TRABAJO se propone recuperar un tema: el municipio, cuyo objetivo es esclarecer la problemática de la política regional desde una perspectiva sociopolítica.

El municipio, como objeto de análisis de las ciencias sociales, tiene ya una larga tradición. Sin embargo, se lo ha tratado fundamentalmente desde un punto de vista jurídico o histórico.

Nuestra pretensión es incorporar al municipio, como institución local de gobierno, dentro del área de estudio de la política regional.

Esta incorporación denota la necesidad imperiosa de ampliar las líneas de trabajo que encara el Area de Estudios Urbanos del Centro de Estudios Económicos y Demográficos.'

Los estudios realizados por el Centro que enfocaron de forma preferencial la política federal regional en México, revelaron la urgencia de contar con un conocimiento más amplio de las realidades regionales a las que se aplica dicha política. En especial se percibió que se carecía de un conocimiento adecuado de las fuerzas sociales existentes en ese nivel y de su vinculación con los aparatos gubernamentales, tanto federales como estatales o lociales.

Por otra parte, el enfoque con el cual se ha realizado nuestro estudio, y que sintéticamente denominamos "sociopolitico", supone estudiar el municipio como el lugar donde se constituyen las relaciones sociales y políticas locales; partiendo de este hecho, puede plantearse su vinculación con las po-

El presente artículo se originó en una invitación que Luis Unikel me realizára para presentar en forma conjunta una ponencia para una reunión que terminó suspendiéndose. Para ello elaboré un borrador de la parte que me habia correspondido. Después, su muy lamentable muerte impidió continuar el trabajo en común. Lo que hice, entonces, fue reelaborar mínimamente dicho borrador para darle forma de artículo, sin poder contar con los comentarios que me habia anunciado. Quiero que esta publicación sea un homenaje a Luis Unikel, con quien tuve la suerte de trabajar durante cinco años, durante los cuales lo respeté como profesional y lo quise como amigo, y a quien debo mucho de lo que he podido realizar en ese tiempo.

1 Véase, especialmente: Lavell, Allan, Pedro Pírez y Luis Unikel, 1978a y 1978b; Unikèl, Luis y Allan Lavell, 1979 y Pírez, P. 1980. 
lític s de los aparatos del gobierno federal. Esto justifica nuestra creencia en la necesidad de ampliar los estudios sobre política regional a una serie de aspectos que deberán incorporar la presencia efectiva de las realidades locales y regionales. EL caso de los municipios es solamente una de esas ampliaciones.

Por otra parte, se dijo al comenzar, que lo que se pretendía realizar era una recuperación. Se trata de conquistar al municipio como un aspecto necesario del análisis de la política regional. Esta inclusión, en tanto recuperación, deberá proponerse cambiar el sentido que han tenido buena parte de los estudios sobre el municipio en México, para someterlo a la lógica del análisis regional. En ese sentido este artículo es solamente el inicio de esa reelaboración.

En principio se hará una breve revisión de la situación político-institucional de los municipios en el régimen legal mexicano; en segundo término se mencionarán algunas dimensiones socioeconómicas que permiten conocer la situación real (no ya legal) de los municipios y, por último, se efectuarán algunas reflexiones acerca de cómo puede iniciarse la recuperación propuesta. Dado el objetivo fundamental del trabajo no se pretende ofrecer un estudio exhaustivo de los municipios en México, motivo por el cual no se menciona su. estado actual, y se limita a utilizar sólo aquellos datos disponibles hasta el año 1976, fecha a la que llegan la mayoría de los estudios antes mencionados.

\section{Los municipios en el contexto político-institucional de México}

La organización municipal actual de México ha sido establecida por la Constitución de 1917. El carácter del municipio en dicha organización institucional está relacionado con la creación y transformación institucionales realizadas como consecuencia del proceso revolucionario. Especificamente, los municipios fueron una reivindicación de algunas fuerzas políticas que, opuestas al régimen porfirista, cristalizaron en dicha Constitución.

La vinculación con los antecedentes del Porfiriato, en el cual los municipios estaban totalmente subordinados al poder central, en especial por la presencia local de los "jefes políticos", parece constituir un elemento importante en la tendencia a generar instituciones políticas que evitasen la repetición de situaciones de sometimiento de las poblaciones a los intereses de algunas minorías.

Los fundamentos doctrinarios que se adoptan para la organización municipal parecieran basarse en dos principios: igualdad política y libertad económica. En la nueva organización se percibe al municipio como un medio para romper el sometimiento de las poblaciones locales al centro nacional.

Tanto es así que Carranza, en su mensaje al Congreso Constituyente al presentar el proyecto de Constitución, afirma que el municipio "es sin disputas una de las grandes conquistas de la Revolución como que es la base del gobierno libre, conquista que no sólo dará libertad política a la vida municipal, sino que también le dará independencia económica, supuesto que tendrá fondos y recursos propios para la atención de todas sus ne- esidades, sustrayéndose así a la voracidad insaciable que de ordinario 
han demostrado los gobernadores, y una buena Ley Electoral que tenga a éstos completamente alejados del voto público y que castigue con toda severidad toda tentativa para violarlo, establecerá el Poder Electoral sobre bases nacionales que le permitirán cumplir su cometido de una manera bastante aceptable" (citado en López González, p. 77).

En suma, la incorporación del régimen de municipios aparece como un resultado directo, e importante, del proceso de institucionalización de la Revolución. Importante porque pretende generar un espacio de vida política autónoma (garantizado por una ley electoral) y con un sistema económico que haga posible dicha vida.

Pareciera que, en tanto espacio de una vida política autónoma, el municipio debe cumplir una función de escuela política, debe ser una instancia de participación ciudadana, debe, en suma, ser el fundamento de la vida democrática del país, a la vez que una institución de socialización cívica. Esta función solamente podrá ser realizada si ellos tienen la capacidad, por una parte, de elegir a sus funcionarios, y por otra, de evitar las interferencias de las autoridades de los otros niveles (estatal y federal), en los asuntos que son, de su competencia.

Además de su reconocido carácter de unidad política y de instancia de ingreso en la vida democrática institucional, tal como fueron pensados en sus principios fundamentales, los municipios pueden operar, según nuestra opinión, como canales de expresión de los intereses de los grupos sociales regionales en relación con las políticas nacionales. Es decir que, pensando en términos de la elaboración de un sistema nacional de políticas regionales, deberían constituirse en los garantes y, a la vez, en los promotores de los intereses de los grupos sociales que serán beneficiados (o perjudicados) por las acciones y políticas del estado federal que se apliquen en sus territorios, $o$ bien que tengan efectos sobre ellos.

Esto debería ser posible ya que ellos representan el orden políticorepresentativo más inmediato de las poblaciones del pais y -especialmente en las zonas rurales o urbanas de menor importancia- prácticamente son las únicas instituciones permeables (por lo menos accesibles) a las poblaciones de menores recursos, no sólo económicos, sino también sociales y políticos.

La concreción de lo antedicho radica en que los municipios tengan capacidad económica, tal como lo señalara Carranza. Esta es la condición final de la libertad política.

En suma, el problema de los ingresos de los municipios se convertirá, como veremos más adelante y como ha sucedido prácticamente en todo régimen de autonomía municipal o aun provincial, en la condición material de existencia de dicha autonomía.

Tal es, muy sintéticamente expuesto, el contexto doctrinario que dio lugar al régimen municipal establecido en la Constitución de 1917. Con algunas reformas posteriores ella establece en su artículo 115, que los estados adoptarán "la forma de gobierno republicano, representativo, popular, teniendo como base de su división territorial y de su organización política y administrativa, el Municipio Libre..." Para ello los municipios serán admi- 
nistrados "por un ayuntamiento de elección popular directa", no debiendo existir autoridad alguna entre ellos y el gobierno estatal. Se determina además, la no reelección inmediata de los funcionarios municipales.

Respecto de los aspectos económicos, el mismo artículo dispone que "los municipios administrarán libremente su hacienda" y que ésta "se formará de las contribuciones que señalen las legislaturas de los Estados"; estableciéndose que tales contribuciones deberán ser "suficientes para atender a las necesidades municipales".

Es decir, constitucionalmente se consagra al municipio como la unidad espacial de las relaciones políticas, dentro de las unidades mayores de los estados, que a su vez se integran en la federación, y se preven las bases materiales (financieras) para que dicha unidad pueda funcionar como tal.

Ahora bien, esta determinación institucional de los municipios no es completa si no se analizan las relaciones previstas con las otras dos instancias de la organización política: los estados y la federación. En ese sistema de relaciones es donde se encuentra la definición real que el sistema legal torga a la institución municipal.

En un nivel estrictamente formal, el sistema de relaciones se define de la siguiente manera: la Constitución Federal crea el municipio, estableciendo las bases fundamentales y los principios políticos, dentro de los que los Estados estructurarán el régimen municipal respectivo. Las Constituciones de las entidades federativas definen las características de sus municipios y establecen las reglas para la distribución de competencias entre los niveles estatales y municipales. Las leyes orgánicas municipales, por su parte, son expedidas por las legislaturas estatales y organizan específicamente los municipios (Gama Torruco, p. 99).

Maś allá de esta vinculación formal existe un conjunto de relaciones sustantivas entre los tres niveles. Dentro de ese conjunto, la trama principal se da en relación con las entidades federativas, y dentro de ellas especialmente con los legislativos estatales. Estas relaciones están normadas por las respectivas constituciones estatales, con base en las disposiciones generales de la Constitución Federal. En términos generales, dichas relaciones son: a) el poder legislativo estatal es, en relación a los municipios, tanto constitucional-local como ordinario; b) establece las contribuciones que podrán cobrar los municipios; c) aprueba anualmente el presupuesto de egresos de cada municipio y la ley de ingresos municipales; d) en algunos casos la legislatura aprueba o veta la disposición que hacen los municipios de sus bienes, tanto públicos como privados, y aprueba las concesiones de servicios públicos y aun los contratos de obras públicas; e) en algunos casos, los municipios cuentan con facultad de iniciativa de leyes ante el Congreso local en asuntos de carácter municipal (Acosta Romero, p. 32 y 33).

Queda claro, al observar las relaciones entre el municipio y el estado local, que - como dice Acosta Romero- "en esos aspectos (los financieros) el municipio no es completamente libre, ya que necesita de la aprobación o consentimiento del Congreso local para realizar actos sobre su patrimonio, y de acuerdo con el espíritu de la Constitución Federal parece evidente que no se ajustan a él" (ibid., p. 33). 
Junto con el control legislativo y financiero que sobre los municipios ejercen las legislaturas de los estados, es necesario agregar el control electoral que, según la mayor parte de las constituciones de los Estados, se ejerce al existir la atríbución de la legislatura o del gobernador del estado para "calificar" las elecciones de los ayuntamientos. Y, por último, el control político que conceden, por lo general, las constituciones estatales al gobierno del Estado bajo la forma de "inspección municipal y de supresión de los ayuntamientos cuando éstos no cumplen su cometido" (Gamas Torruco, p. 117 a 120).

Por otra parte, el peso de los gobernadores dentro de sus respectivos estados supone "un poder que no se equilibra con ninguno de los otros (del Estado), y su preponderancia es tal, que él designa tanto a los funcionarios de las dependencias administrativas como a los funcionarios del poder judicial". Por lo demás, el gobernador da las directivas dentro del partido político al que pertenece para seleccionar a los candidatos para integrar el Congreso local y los ayuntamientos; de alli que desde un punto de vista estrictamente político, exista una relación directa (dependiente) entre los alcaldes, los síndicos y los regidores con el gobernador del estado. (Acosta Romero, p. 34).

Deben agregarse a lo anterior, las relaciones de los municipios con los poderes federales, en particular con el ejecutivo y las organizaciones que de él dependen. Al respecto, baste decir que las principales, sino únicas acciones de promoción de las actividades y del desarrollo económico y social en general son tomadas -en todo el territorio del pais- por las dependencias del ejecutivo federal, sea a través de las Secretarías de Estado o por medio de organismos intermedios y descentralizados.

Más aún, a nivel nacional es muy importante tener en cuenta el peso del Partido Revolucionario Institucional que, como dice Acosta Romero, aun cuando no es una dependencia federal, tiene una "relación primordial y fundamental" con los municipios, "ya que en un porcentaje elevadísimo la mayoría de los miembros de los ayuntamientos de la República que llegan a gobernarlos son personas con militancia por lo menos formal en ese instituto político, y dentro de él las fuerzas reales de poder son las que orientan la designación de los candidatos a los cargos municipales" (ibid., p. 30).

Esta última vinculación con el poder nacional se da, por lo general, mediada por las funciones de los gobernadores, dado el peso que tienen dentro del Partido en sus estados. Es por ello que puede afirmarse que, "para ciertos municipios el factor preponderante sea el gobernador del Estado, o aun funcionarios superiores" (ibid.).

Esta rápida revista de la definición institucional de los municipios indica una situación algo contradictoria: por una parte, los principios fundamentales que establece la Constitución Federal tienden a fundar la autonomía y libertad de los órganos municipales, tanto en lo político como en lo económico. Por otra parte, con base en algunas disposiciones de esa misma constitución y de las constituciones de los estados locales, los municipios son subordinados a las órdenes institucionales "superiores". La concreta organización de las relaciones políticas, entre estado y federación, tal como se 
vio, colocan a los municipios en una posición subordinada políticamente en relación con los estados y la federación.

Dicha contradicción es, en nuestra opinión, las base institucional del proceso de centralización política y de pérdida de importancia y de atribuciones reales de los municipios. En suma, nuestra hipótesis es que la dependencia de los municipios no se construye exclusivamente en términos económicos y financieros, sino que se construye por una subordinación en las relaciones políticas nacionales.

Esta subordinación política es parte de un proceso de centralización y concentración del poder político que tiene lugar desde el inicio de la institucionalización posrevolucionaria. En un principio se explica por la necesidad de terminar con la existencia de poderes regionales potencialmente competitivos con el poder de la Revolución que se encarnaba en el ejecutivo nacional: necesidad sobre todo de terminar con los generalescaudillos políticos que podían poner en peligro la institucionalización del proceso. Dicha concentración fue parte del movimiento de imposición de nuevas formas institucionales, nacidas de una revolución, a una sociedad bastante convulsa aún. Luego, el proceso de concentración, una vez ya efectivizada la institucionalización política del país, se vio impulsado por la necesidad de instaurar un modelo de desarrollo que se basara, de un modo predominante, en el peso de la acción y la presencia de la federación. En especial a partir de 1940 se completa la concentración con la implementación de un modelo de desarrollo que, al dar prioridad al crecimiento acelerado de la industria, subordinó el desarrollo de las relaciones económicas rurales al de las relaciones urbano-industriales. Esto último fue posible, en parte, por la existencia de una importante centralización política que, tanto en los aparatos de estado que se implementaron como en el funcionamiento del partido oficial, constituyó la infraestructura político-institucional de la concentración económica y del creciente proceso de subordinación de los órdenes municipales y estatales a la federación.

Las consecuencias más importantes de este doble proceso concentrador fueron: por una parte, la no efectivización del municipio en lo que ha sido llamado "escuela de la vida civil y política" y, por la otra, la ineficacia del mismo como canal de desarrollo y expresión de los intereses regionales frente a los intereses del "centro".

\section{El contexto socioeconómico de los municipios en México}

La situación socioeconómica de los municipios en México se caracteriza por su heterogeneidad y desigualdad. Estas características abarcan un conjunto muy amplio de dimensiones naturales y sociales: desde su extensión y población hasta el nivel de sus ingresos fiscales. Por lo demás, es extremadamente diferente la realidad de los municipios en relación con los distintos estados. Por ejemplo, los 2377 municipios con que cuenta el pais se distribuyen de modo diferencial entre las entidades federativas: desde el estado de Oaxaca que tiene 571 municipios, pasando por los estados de Puebla con 222, Veracruz con 198, México con 119, Michoacán con 111, Chihuahua x Actuphents:5 5 pos. 
con 66, Coahuila con 38, Morelos con 32, hasta Baja California con 4 (López González, p. 90).

Más dramática aún es la situación socioeconómica de los municipios y sus desigualdades en ese campo.

Para dar una idea de las desigualdades socioeconómicas, mencionaremos solamente tres indicadores: ingreso, vivienda y analfabetismo. ${ }^{2}$

En 1970, el ingreso medio per cápita anual de la población de casi la mitad de los municipios no era mayor de 1500 pesos, y en el $87.93 \%$ de los casos ese ingreso no superaba los 6000 pesos. Mientras tanto, la población del $1.08 \%$ de esas entidades recibía un ingreso medio anual de más de 30000 pesos. (véase cuadro 1).

\section{Cuadro 1}

MEXICO: INGRESO PER CÁPITA ANUAL POR MUNICIPIOS, 1970

\begin{tabular}{|c|c|c|}
\hline $\begin{array}{l}\text { Rangos d } \\
\text { (en }\end{array}$ & $\begin{array}{l}\text { de Ingreso } \\
\text { pesos) }\end{array}$ & $\begin{array}{l}\text { Porciento de } \\
\text { Municipios }\end{array}$ \\
\hline 0 & a 1500 & 47.978 \\
\hline 1501 & a $\quad 6000$ & 39.968 \\
\hline 6001 & a 12000 & 7.128 \\
\hline 12001 & a 30000 & 3.778 \\
\hline $30 \quad 001$ & Y mas & 1.088 \\
\hline
\end{tabular}

FUENTE: Secretaria de Programación y Presupuesto. México Socioeconómico, México, 1978.

En el $15.26 \%$ de los municipios más del $15 \%$ de las familias que ahí viven carecen de vivienda, en el $36.85 \%$ de esas entidades es más del $10 \%$ la proporción de familias que aún no tienen vivienda, y solamente en una tercera parte de los municipios les falta vivienda a no más del $5 \%$ de las familias (véase cuadro 2).

Cuadro 2

MEXICO: FAMILIAS SIN VIVIENDA POR MUNICIPIOS (PORCIENTOS) 1970

\begin{tabular}{rrrrr}
$\begin{array}{c}\text { Porciento de familias } \\
\text { sin vivienda }\end{array}$ & $\begin{array}{c}\text { Porciento de } \\
\text { Municipios }\end{array}$ \\
\hline 0 & a & 5 & 33.448 \\
6 & a & 10 & 29.718 \\
11 & a & 15 & 21.598 \\
16 & a & 20 & 11.048 \\
21 & a & 33 & 4.228 \\
\hline
\end{tabular}

FUENTE: Idem. cuadro 1.

2 Lal utilización de los indicadores mencionados. y no de otros, es en cierta medida una decisión arbitraria. De todas formas creemos que poseen capacidad explicativa y dan cuenta de la realidad en forma amplia. 
Con relación al analfabetismo de la población mayor de 10 años, solamente una cuarta parte de los municipios presenta no más del $20 \%$ de analfabetas, mientras que en casi el $30 \%$ de esas organizaciones es más del $40 \%$, y en el $7.41 \%$ de los municipios más de las dos terceras partes de esa población es analfabeta (véase cuadro 3.).

\section{Cuadro 3}

MEXICO: MAYORES DE 10 AÑOS ANALFABETOS POR MUNICIPIOS (POR CIENTOS) 1970

\begin{tabular}{|c|c|c|c|}
\hline $\begin{array}{l}\text { Porcientos } \\
\text { de } 10 \text { años }\end{array}$ & $\begin{array}{l}8 \text { de mayores } \\
5 \text { analfabetos }\end{array}$ & & $\begin{array}{l}\text { Porcientos de } \\
\text { Municipios }\end{array}$ \\
\hline 3 & a 20 & & 25.70 \\
\hline 21 & a 40 & & 45.50 \\
\hline 41 & a $\quad 60$ & . & 21.37 \\
\hline 61 & a 75 & & 5.68 \\
\hline 76 & a 94 & 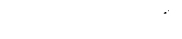 & 1.73 \\
\hline
\end{tabular}

FUENTE: Idem. cuadro 1.

Los indicadores utilizados, aunque parciales, dan una idea de las desigualdades que existen entre los municipios del país y, además, del bajo nivel de desarrollo socioeconómico que caracteriza a la mayor parte de los mismos. Puede afirmarse que, comparativamente, la mayor parte de los municipios del país se encuentran en situación de atraso socioeconómico. Especialmente con relación a la atención de las necesidades fundamentales de la población y la promoción de las actividades económicas.

La "triste situación" que caracteriza a los municipios en los aspectos mencionados se debe, en gran medida a la inequitativa distribución de los recursos públicos entre los tres niveles de la organización gubernamental, y en particular, a su concentración en la Federación.

Analizando en términos generales la situación financiera de los municipios mexicanos, en relación con las otras dos instancias gubernamentales (estatal y federal), se observa un paulatino deterioro, una pérdida creciente de capacidad financiera $y$, en consecuencia, una tendencia a poder solventar casi con exclusividad, lo que podría denominarse su "sobrevivencia administrativa".

Estudiando la tendencia general, desde 1940 a 1970 , de la distribución proporcional de los ingresos públicos para cada una de las tres instancias, se observa que los estados mantienen una misma proporción, si bien con altibajos, superando apenas el 20\%; mientras que los ingresos municipales disminuyen y se incrementan los federales. Pareciera que la tendencia es la absorción por parte de la Federación de los ingresos que eran captados por los municipios $y$, en menor medida, también por los estados.

Como puede observarse en el cuadro 4, los ingresos federales que en 1940 eran el $71.4 \%$ del total, llegan en 1970 al $76.24 \%$, mientras que los mu- 
nicipales descienden del $5.30 \%$ al $1.5 \%$ entre esas mismas fechas. Los ingresos de los estados que en 1940 constituian el $23.30 \%$, en 1970 son el $22.26 \%$.

Esta información indica que los municipios, además de haber tenido siempre una participación baja dentro del ingreso, progresivamente están perdiendo la capacidad de atender los problemas de la población. Se puede afirmar entonces que ese sistema nacional de reparto de los ingresos imposibilita que los municipios enfrenten los problemas de sus poblaciones.

\section{Cuadro 4}

MÉXICO: INGRESOS DE LA FEDERACION, LOS ESTADOS Y LOS MUNICIPIOS 1940-1970 . (PORCIENTOS)

\begin{tabular}{lcccc}
\hline Años & \multicolumn{3}{c}{ Ing r e s o s } & Municipal \\
\cline { 2 - 5 } & Total & Federal & Estatal & 5.30 \\
1940 & 100 & 71.40 & 23.30 & 3.35 \\
1950 & 100 & 79.37 & 17.28 & 2.84 \\
1970 & 100 & 78.56 & 18.60 & 1.50 \\
\hline
\end{tabular}

FUENTE: Unikel, Garza y Ruiz Ch., cuadro VIII-15 p. 273.

Al observar la participación de las tres instancias gubernamentales en el gasto público enconiramos la misma tendencia que en el caso de los ingresos (véase cuadro 5). El gasto federal que en 1940 era el $73.71 \%$ del total, constituyó en 1970 el $75.24 \%$; mientras que a nivel estatal, en esos mismos años, se verifica el $21.39 \%$ y el $21.85 \%$ del gasto total respectivamente. Los municipios por su parte, participaron en 1940 con el $4.90 \%$ del gasto, en 1970 con el $2.91 \%$ y en 1976 con el $1.7 \%$.

Cuadro 5

MEXICO: GASTOS DE LA FEDERACIÓN, LOS ESTADOS Y LOS MUNICIPIOS 1940-1976. (PORCIENTOS)

\begin{tabular}{lcccc}
\hline \multirow{2}{*}{ Años } & \multicolumn{3}{c}{ Gas t o s } & Municipal \\
\cline { 2 - 4 } 1940 & Total & Federal & Estatal & 4.90 \\
1950 & 100 & 73.71 & 21.39 & 3.29 \\
1960 & 100 & 77.99 & 18.72 & 2.77 \\
1970 & 100 & 79.61 & 17.62 & 2.91 \\
1976 & 100 & 75.24 & 21.85 & 1.70 \\
\hline
\end{tabular}

FUENTE: Años 1940 a 1970: Unikel, Garza y Ruiz, cuadro VIII-15 año 1976: Mori. p. 35.

Analizando la información sobre la participación de los municipios en los ingresos y gastos públicos (cuadros 4 y 5 ), se encuentra una peculiari- 
dad: los municipios tienen una participación cada vez mayor en los gastos que en los ingresos. Esto significa que "la diferencia es cubierta en parte por los gobiernos estatales y en parte por el federal" (Unikel, Garza y Ruiz Ch., p. 274). Dicha diferencia, en el año de 1970, llega a ser casi del doble.

La situación de deterioro financiero municipal se debe a que las fuentes impositivas que están a disposición de los municipios son insuficientes, a diferencia de lo que ocurre con las otras instancias, especialmente con la federal. Por otra parte, en relación con esas fuentes, "los impuestos van perdiendo importancia relativa y se recurre cada vez más a los productos y aprovechamientos, sin que los gobiernos superiores se muestren dispuestos a entregar fuentes de ingreso a los municipios" (ibid., p. 274).

Dada su situación financiera, los municipios deben dedicar la mayor parte de su gasto a mantener la administración, a veces en condiciones muy lamentables. Así, entre 1960 y 1967, destinaron en promedio más del $60 \%$ de su presupuesto a gastos administrativos; a obras públicas y fomento dedicaron entre el $24.1 \%$ y el $22.8 \%$; a gastos de transferencia el $5.8 \%$ (en 1967) y al pago de la ddeuda pública el $7.5 \%$ (en 1967) (Ibid. p. 280).

Hemos indicado la situación financiera media de los municipios mexicanos. Pero es importante pensar que, dentro de ese promedio, se dan situaciones de gran desigualdad. Baste mencionar, a modo de ejemplo, algunas diferencias en el presupuesto municipal per cápita: para 1970, el municipio de Acapulco en el estado de Guerrero presentaba un presupuesto per cápita de 118 pesos, el de Tijuana en Baja California Norte de 161 pesos; mientras que el municipio de Cuicatlán de Oaxaca tenía un presupuesto per cápita de 11 pesos y el de Villa de Allende del Estado de México de 2.70 pesos por persona (Muñoz y Ruiz Massieu, p. 128).

Los municipios que cuentan con mayores recursos son aquéllos que se encuentran en las regiones - ya sean rurales o urbanas- más desarrolladas del país. Corresponde a tres tipos de regiones la presencia de municipios con mayores recursos: a) a las zonas agrícolas prósperas, de economía agrícola capitalista altamente tecnificada: municipios de Mexicali, Torreón, Culiacán, Cajeme, Matamoros, Tamaulipas, Navojoa, Ahome y San Luis Río Colorado; b) a las zonas industriales más importantes del país, exceptuando al Distrito Federal: municipios de Guadalajara, Monterrey, Puebla, San Luis Potosí, León, Guanajuato, Tlalnepantla, Irapuato, Orizaba, Cuernavaca, Naucalpan, Poza Rica y Querétaro; c) a los puertos marítimos y a la zona fronteriza norte: municipios de Ciudad Juárez, Tijuana, Mazatlán, Veracruz, Tampico, Guaymas, Nogales, Coatzacoalcos y Nuevo Laredo (López González, p $\bar{p} .92$ y 93).

Con base en la información mencionada se percibe una clara tendencia a la centralización de los recursos en el nivel federal y, consecuentemente, a la pérdida por parte de los municipios de la posibilidad de incidir en la solución de los problemas de sus poblaciones. De allí que como "muchos gobiernos locales, especialmente los de las ciudades no pueden hacer frente a las crecientes necesidades de infraestructura urbana y de servicios públicos adecuados..." (Unikel, Garza y Ruiz Ch. p. 273), estas necesidades deben ser cubiertas con los ingresos correspondientes a las otras instancias, espe- 
cialmente las del gobierno federal, con la consiguiente pérdida de autonomía por parte de los municipios. ${ }^{3}$

Funciones y realidades de los municipios en el contexto del desarrollo regional

Veamos ahora cuáles son las funciones que, al menos formalmente, se asignan a los municipios.

A este respecto no existe coincidencia entre los especialistas debido simplemente a la forma cómo, desde la Constitución Federal, se ha organizado el otorgamiento de dichas funciones. La enumeración más completa encontrada la aporta Gamas Torruco, quien distingue entre "funciones" y "atribuciones" del municipio.

Entre las funciones del municipio, el autor cita las siguientes: a) en el orden federal, actuando como "órgano auxiliar de la federación", el municipio cumple y hace cumplir las leyes respectivas y las reglamenta, en este último caso, cuando así le sea encomendado; b) en el orden local, como "órgano auxiliar de los Estados", cumple y hace cumplir las leyes estatales y las reglamenta cuando se le encomienda; c) expide la ordenanza municipal y la aplica a los casos concretos.

Por otra parte, según Gamas Torruco, el municipio debe desarrollar actividades que constituyen su esfera de competencia: a) planificación municipal: desarrollo de las áreas territoriales que la integran en relación con los recursos de que disponga, integración en planes regionales, estatales y federales; b) zonificación; c) salud pública; d) servicios públicos; e) educación; f) promoción económica; g) materia hacendaria: preparación del presupuesto y de la cuenta pública, contratación de obligaciones y empréstitos, recaudación y administración de ingresos; h) trabajo y previsión social; i) esparcimiento; j) salubridad; y k) suministros (Gamas Torruco, pp. 115 a 117)

De acuerdo con la fracción IV del artículo 115 de la Constitución Federal, corresponde al Municipio, en el ámbito de su competencia, expedir las disposiciones que sean necesarias para el ordenamiento y regulación de los asentamientos humanos, en lo que se refiere a los centros urbanos. Es decir, los municipios constituyen también una instancia de planificación, referida al ordenamiento del territorio que tienen a su cargo.

Si a lo anterior se suma la gran cantidad de tareas que significa hacerse cargo de la provisión de los servicios públicos -especialmente en los centros urbanos (agua potable, drenaje, limpieza, pavimentación, policía, transportes, etc.)-, se puede coincidir en la importancia político-

3 Si bien, como mencionamos en la Introducción, no pretendemos hacer una descripción actualizada de la situación de los municipios en México, el contexto socioeconómico que hemos planeado parece no haber cambiado en términos sustantivos. Esto último puede comprobarse al leer las conclusiones de la Junta de Evaluación del Programa de Fortalecimiento Municipal realizada en Oaxtepec en enero de 1981. En ellas los municipios pidieron "mayor equilibrio de la Federación en la captación y distribución de los recursos tributarios" y señalaron "la necesidad de fortalecimiento de la hacienda municipal mediante un incremento de la participación en los impuestos estatal predial y federal a la explotación de recursos naturales...". (Excélsior, p. 4). 
administrativa que la organización institucional otorga a los municipios.

Paradójicamente, frente a la atribución de un conjunto de facultades y funciones que operan como un elemento que define las características del sistema federal de gobierno, se encuentra una serie de "relativizaciones" de esas atribuciones propias de la autonomía municipal. Es decir que, en términos políticos, existe cierta subordinación, tanto institucional como funcional, de los municipios a los otros órdenes, en particular al federal.

Pero más allá de la subordinación política, la limitación financiera de los municipios es, a nuestro entender, la causa inmediata de la situación socioeconómica y de la imposibilidad de realizar buena parte de los objetivos de la organización federalista.

Repetimos, la situación financiera de los municipios tiene consecuencias más allá de los obvios efectos socioeconómicos. En términos políticos contribuye al original deterioro relativo -en relación a los otros poderesde la organización municipal. La tendencia a la centralización de los recursos en el nivel federal significa necesariamente la pérdida por parte de las fuerzas sociales locales, de la posibilidad de incidir en las decisiones que las afectan en el uso de los recursos públicos. Los municipios dejan de ser por ello una instancia real de decisión de las políticas que determinan los cambios o transformaciones importantes, tanto en lo que se refiere a la producción de los soportes materiales para la realización de actividades sociales y económicas, a la provisión de condiciones generales de la producción y a la promoción de dichas actividades, como al bienestar general de la población. En suma, el municipio no cumple el papel que, dentro del juego de fuerzas políticas a nivel regional, podría jugar en la dinámica entre el centro y las regiones, especialmente en la emergencia de los intereses de los grupos sociales regionales y locales. Esto quiere decir que una de las dimensiones de la organización federal, la relativa a la autonomía institucional de las fuerzas locales frente a la federación (el "centro" político) no ha desarrollado, aparentemente, sus posibilidades reales de implementación.

La lamentable situación financiera y político-institucional de la mayor parte de los municipios ha producido dos efectos inmediatos: la poca incidencia de los municipios en las decisiones referidas a buena parte de las condiciones de la vida cotidiana de sus habitantes y, por otra, la dificultad de su desenvolvimiento administrativo normal. Lo primero ha contribuido a la despreocupación de los habitantes sobre la necesidad de participar en la vida política local, dada la poca importancia efectiva que ésta tiene para sus vidas cotidianas, o bien ha conducido a una participación en términos del cumplimiento de lo que llamamos el primer escalón en las carreras individuales en la vida político-partidaria-gubernamental. Pero, para el ciudadano medio, el municipio no funciona como la instancia de participación y decisión en los aspectos que se vinculan más directamente con las condiciones de su vida cotidiana, ni es el canal de inserción en los aparatos estatales superiores. En ese sentido ofrece poco atractivo. Por el contrario, son las otras instancias, en especial la federal, las que deben atraer la atención de los ciudadanos en sus intentos de lograr efectos reales 
sobre sus situaciones. En este caso pareciera que, cuanto más lejana es la instancia mayores posibilidades tiene ésta de incidir en las condiciones de vida de la población de los municipios, pero al mismo tiempo, menos puede el ciudadano medio incidir sobre ellas. Consecuentemente, las decisiones sobre ciertos aspectos que afectan directamente la vida de los ciudadanos son tomadas en esas instancias, por lo general, muy alejadas de ellos. Así la falta de posibilidades materiales de los municipios contribuye, en forma muy significativa, a colocarlos en relaciones de subordinación dentro del ordenamiento político-institucional.

La grave situación económica impide además, en muchos casos, la simple existencia de las instituciones municipales, no solamente su acción representativa de los intereses locales. Más aún, la responsabilidad municipal se vuelve una carga insostenible para muchos habitantes de las regiones más pobres del país; tanto es así que "en el estado de Oaxaca (570 municipios), se ha tenido que proceder al encarcelamiento de alcaldes electos (50 en 1977), para obligarlos a tomar posesión de su cargo. En muchos municipios de nuestro país, incomunicados y con menos de un peso de presupuesto diario, la posibilidad de llegar a la presidencia municipal se convierte en un temor entre los hombres de edad madura; para ellos huir del 'poder' constituye la esperanza" (Muñoz y Ruiz-M., p. 129).

Los hechos que se han mencionado - y dado que los municipios deberian ser el ámbito natural para la emergencia y organización de las fuerzas sociales de base local y para la constitución de agrupamientos entre los grupos sociales en torno a sus intereses local y regionalmente definidossignifican la frustración de una instancia efectiva de defensa de dichos agrupamientos de intereses. En este caso, nuestra hipótesis es que la falta de ese "habitat" político local que sustente dichas fuerzas sociales y que permita cierta instrumentación dentro de la organización institucional nacional, obstaculiza no sólo la organización de esos intereses sino también sus posibilidades de enfrentar a los poderosos mecanismos del "centro" político y económico.

De allí la importancia del municipio en relación con las políticas y planes nacionales destinados al "desarrollo regional".La centralización política que impide la existencia de canales e instituciones para la gestación, organización y expresión nacional de los intereses de los grupos locales y regionales conduce, en cierta medida, a que los planes regionales, diseñados y producidos por el estado federal se efectivicen con la finalidad fundamental de articular las realidades sociales y económicas locales y regionales a las necesidades del desarrollo de los sectores "centrales" del país.

\section{A modo de conclusión}

La recuperación del tema del municipio para el estudio de la planificación regional no debe quedar en el nivel de las lamentaciones. En consecuencia, es necesario realizar una integración positiva.

Dicha integración positiva deberá significar el desarrollo de las posibilidades de reversión de la situación que hemos descrito 
sucintamente, y ese trabajo requiere fundarse en la hipótesis de la posibilidad de dicha reversión. Una vez aceptada ésta, es necesartio entonces, diseñar mecanismos para su logro.

En relación con lo que nos atañe en forma directa - el conocimiento de la realidad-, creemos que la tarea propuesta tiene una gran importancia en la medida en que la posibilidad de reversión no puede plantearse sino como resultado del conocimiento acabado de los municipios y del desarrollo, con base en ese conocimiento, de estrategias de acción.

Se hace necesario así, el estudio concreto de la realidad municipal y de su vinculación con el sistema de planificación regional. En una primera instancia, dicho estudio debe tratar de conocer a los municipios como recortes de base territorial de la sociedad nacional dentro del contexto regional. En ese intento se deberá construir la trama de relaciones sociales que los actores fundamentales que existan a nivel municipal (en algún caso concreto), entablan entre sí, y que puede interpretarse como el sistema social municipal. Al realizar esto se estará describiendo una unidad territorial mínima de organización social y, por eso mismo, la que pudiera presentar mayores posibilidades de integración de las diferentes fracciones sociales en la discusión y decisión en la planificación, tanto en ese nivel como en relación con los superiores.

El segundo elemento que es necesario estudiar se refiere a la integración de los municipios en el sistema (formal) de la planificación regional nacional: tratando de reconstruir la estructura que, compuesta por la organización municipal en un extremo, llega hasta los aparatos federales, en el otro.

Con base en los estudios indicados podrá fundarse la hipótesis de la posible reversión de la situación del municipio; para ello será decisivo el conocimiento del posible juego entre las fuerzas sociales locales, regionales y nacionales y. el papel que en dichas relaciones cumple (y sobre todo puede cumplir) el municipio.

\section{BIBLIOGRAFÍA}

Acosta Romero, Miguel, “Relaciones entre el Municipio, la Federación y las entidades Federativas" en R. Jiménez Ottalengo y J. Moreno Collado, Los Municipios de México, UNAM, México, 1978.

Constitución Política de los Estados Unidos Mexicanos.

Excélsior, México, 28 de enero de 1981.

Gamas Torruco, José, “El marco juridico del Municipio Mexicano" en R. Jiménez Ottalengo y J. Moreno Collado, op. cit.

Lavell, Alan; Pedro Pirez y Luis Unikel, 1978a. "El Estado y la cuestión regional en México", Seminario sobre la cuestión regional en América Latina, México, abril de 1978. 
Lavell, Allan; Pedro Pírez y Luis Unikel, 1978b. "La planificación del desarrollo y la redistribución espacial de la población: El caso de México: 1940-1978", Seminario sobre redistribución espacial de la población, CELADE, Santiago, agosto de 1978.

López González, Valentín, Evolución del Municipio en México, Tesis profesional. Escuela de Derecho y Ciencias Sociales, Universidad Autónoma del Estado de Morelos, s/f.

Mori, Antonio, "Los Municipios fantasmas" en Nexos, no. 35, México, noviembre de 1980.

Muñoz, Virgilio y M. Ruiz Massieu, Elementos Jurídico-Históricos del municipio en México, UNAM, México, 1979.

Pírez, Pedro, 1980. "Política regional y concentración urbana en México" en CIDIV, año 3, no. 13, mayo-junio de 1980. INDECO, México.

Unikel, Luis, G. Garza y C. Ruiz Ch., El desarrollo urbano de México, El Colegio de México, México, 1976.

Unikel, Luis y Allan Lavell, 1979, "El problema urbano-regional en México" en Gaceta UNAM, cuarta época, vol. III, suplemento número 20, 9 de agosto de 1979, México. 